\title{
Fourth-Year Engineering Students' Descriptions of the Importance of Im- proving Society Through their Engineering Careers
}

\section{Dr. Greg Rulifson P.E., Colorado School of Mines}

Greg currently teaches sustainable community development in Humanitarian Engineering at CSM. He earned his bachelor's degree in Civil Engineering with a minor in Global Poverty and Practice from UC Berkeley where he acquired a passion for using engineering to facilitate developing communities' capacity for success. He earned his master's degree in Structural Engineering and Risk Analysis from Stanford University. His PhD research at CU Boulder focused on how student's connections of social responsibility and engineering change throughout college as well as how engineering service is valued in employment and supported in the workplace.

\section{Dr. Angela R. Bielefeldt, University of Colorado, Boulder}

Angela Bielefeldt is a professor at the University of Colorado Boulder in the Department of Civil, Environmental, and Architectural Engineering (CEAE), where she serves as the ABET assessment coordinator. She is the faculty director of the Sustainable By Design Residential Academic Program, a living-learning community where interdisciplinary students learn about and practice sustainability. Bielefeldt is also a licensed P.E. Her research interests in engineering education include service-learning, sustainable engineering, social responsibility, ethics, and diversity. 


\title{
Fourth Year Engineering Students' Descriptions of the Importance of Improving Society Through their Engineering Careers
}

\begin{abstract}
As engineering students graduate and enter the workforce, they gain significant responsibility for individuals and society through their future decisions. Problematically, multiple recent studies have shown that over their time in college, students tend to become more disengaged from the impact of their work and their feelings of social responsibility decrease. The question explored in this research was to determine the extent that fourth year engineering students discuss helping others and society through their careers as an aspect of an ideal job or an aspect that would make their work rewarding. Hour-long, semi-structured interviews were conducted with twenty engineering undergraduate students near the end of their fourth year of college. These students were attending five different universities and pursuing six different majors (primarily mechanical and civil engineering). Student responses, while unique to their personal situation, fell into four categories regarding their visions for a future ideal engineering career: (A) helping people and society was the most important component to their future engineering career; (B) helping people and improving society was listed as a component to their ideal career; (C) after being asked what would be rewarding, the student mentioned having a positive impact on society or people, or that their work would naturally help society because that is inherent in engineering; and (D) helping people or improving society was not mentioned as part of their ideal career or an aspect that would be rewarding in their work as an engineer. Students in group A through $\mathrm{C}$ described that they would try to work on projects that improved the environment, local communities, and society at large. Group D students would not be looking for a particular engineering job that would help people and did not seem to be concerned with the impact of their job. They prioritized interesting work, location, and sometimes salary over the degree to which their work would help society overall. No obvious differences were evident in the institutions or majors of the students who clustered into the different response categories, but internships and general confidence in their engineering abilities did seem to have an influence. The paper will finally offer an analysis of possible reasons for these outcomes, and how faculty and the engineering profession more broadly can improve graduating engineers' perceptions of and goals for their future careers.
\end{abstract}

\section{Introduction}

The engineering profession has a profound impact on society. The extent to which engineers in the profession have a goal to improve society or help people through their work gives insight as to which priorities may drive choices on engineering projects and how intentional engineers are about optimizing their work's ability to create positive change. Only with engineers in the profession that believe and express that their work improve society can the profession actually achieve this ethos.

Engineering has a long and complicated relationship with its impact on society. Layton describes how engineers' belief in Spencerism allowed them to perceive their work as inherently valuable and just since they were making the societal organism more advanced ${ }^{1}$. Further into the $20^{\text {th }}$ 
century, while most engineering professionals were integrated with the United States' Cold War ideologies, some engineers of the 1960s and 70s began to move beyond the materialism of previous decades, avoided the ills of technology, and took responsibility for improving society for all ${ }^{2}$. The Institute of Electrical and Electronics Engineers (IEEE) codified their ethics in 1912 and the American Society of Civil Engineers (ASCE) and American Society of Mechanical Engineers (ASME) soon followed in 1914,3. These codes defined the relationship of engineers to society, but also to their clients and employers who were to receive an engineer's deference and gratitude. These codes have continued to evolve to an extent, but represent a minimum standard which engineers must achieve and have always been wrapped up in concerns of the nation and corporations ${ }^{5}$.

Engineering education in the U.S. has largely paralleled the goals of the nation. During the Cold War, engineering science was the overwhelming focus to produce engineers that could contribute to the war effort. The Science and Technology Studies (STS) movement in higher education grew out of the concern for environmental and social welfare of the 1970s, and some universities (UCLA, Harvey Mudd, MIT, CalTech) did try to integrate the humanities with a strong technical education ${ }^{2}$. Their efforts, however, were challenged through the nation's neoliberal policies of the 1980s that reduced government regulations on corporations in which engineers worked. An ability to compete and win in the global market continued to be the overarching goal through the $1990 \mathrm{~s}^{5}$. The $21^{\text {st }}$ century brought on a new threat, terrorism, and with it, a new goal of security for the engineering profession. At the same time, the Engineering to Help explosion began, and thousands of engineering students began their involvement with poverty alleviation efforts around the globe ${ }^{5}$. The largest among them is Engineers Without Borders (EWB) USA, which has grown to over 14,000 members in student and professional chapters around the country ${ }^{6}$. While a large number, it still represents a small fraction of those students participating in and graduating from their technical engineering educations and joining the workforce.

With this background, scholars have called on students and engineering educators to learn and teach about the deeper impacts that engineering products have on various social groups and environments. Herkert considers the difference between microethics found in codes and macroethics which consider differential effects on marginalized groups, downstream environmental effects, and potential unforeseen hazards of a technology or infrastructure as society changes ${ }^{7}$. In The Citizen Engineer, readers are encouraged to use their high level of education and privileged position in society to take on more responsibility and try to have a larger and longer-lasting positive impact on the world ${ }^{8}$.

Finally, it is in society's best interest for engineering education to prioritize learning about macroethics and the ways engineers can improve society. The National Academy of Engineering (NAE) produced two reports that speak to this importance. The Engineer of 2020 describes how future engineers need to be able to engage beyond their calculations and cubicles as the world changes and demands professionals who can think critically about and work on the toughest challenges 9 . In Changing the Conversation, the authors explain that in order for the engineering profession to most effectively address society's biggest issues, it must present itself as a career with a strong, pro-social and environmental impact to recruit more diverse students with a desire to improve society ${ }^{10}$. Multiple other studies have shown that girls are more attracted to professions with a perceived positive social impact ${ }^{11-13}$, and women are more likely to persist in engineering if they have some service component to their college experience ${ }^{14,15}$. Even though 
research has shown the importance of including and promoting education about the value of engineering to society, other studies point to a culture of engineering still characterized by a lack of empathy, social relevance, and emotion ${ }^{16-18}$. Students seem to internalize this environment as they progress through college, and graduate with decreased social responsibility and public welfare beliefs ${ }^{16,19}$.

While engineering clearly does have a large impact on society, and the positive aspects of this impact can be tools for recruitment and retention of underrepresented students, it is still unknown how students perceive and value the impact they could have on society through their careers.

\section{Research Question}

This research seeks to understand how fourth year engineering students incorporate and prioritize the ideas of helping people and improving society into their envisioned ideal future careers. In addition, influences on these ideas of helping were explored.

\section{Methods}

This study is a portion of a four-year longitudinal study of how engineering students' ideas about social responsibility and engineering change over their time in college ${ }^{20-22}$. Students were initially contacted through the Engineering Professional Responsibility Assessment (EPRA) ${ }^{23}$ distributed in the Fall of 2012 and recruited using criterion-based selection ${ }^{24}$. In this fourth and final year, twenty students participated who had been interviewed in the previous years. They represented six majors, five universities, and a range of initial social responsibility (SR) attitudes as measured by the average score on 50 Likert-type items (item scale 1 to 7 ; resulting in average scores from 4.68 to 6.55$)$. The universities attended by the students were a large public researchintensive university (LPU, n=5), a technically-focused medium-sized public university (TU, $\mathrm{n}=7$ ), a medium-sized public university (MPU, $n=2$ ), a medium-sized private research intensive university (PrU, n=5), and another medium sized public university (MPU2, n=1) to which one student transferred. See Table 1 below for the student demographics. Interviewees included 11 female and 9 male students, with a majority majoring in mechanical engineering $(n=7)$ and civil engineering $(n=7)$ in year 4 . Initial average scores on the social responsibility items are also shown.

As in previous years, students were offered a $\$ 100$ Amazon gift card incentive to participate. Interviews in this fourth year were conducted from March - April 2016, lasted 60-120 minutes, were conducted over the phone, recorded, and transcribed verbatim using Nuance Dragon software and Microsoft Word. Pseudonyms were assigned to the students before the first interview using typical conventions ${ }^{25}$. Students were also asked to complete the online EPRA survey, with a $\$ 10$ gift card offered as incentive. 
Table 1: Interviewed Student Demographics

\begin{tabular}{|ccccc|}
\hline Pseudonym & Gender & School & Yr 4 Major & Y0 Avg SR Score \\
\hline Ashley & F & PrU & Chemical & 5.62 \\
Brandon & M & TU & Mechanical & 5.82 \\
Denise & F & PrU & Mechanical & 5.96 \\
Derek & M & PrU & Mechanical & 6.34 \\
Jamie & F & TU & Mechanical & 5.62 \\
Jason & M & TU & Civil & 4.68 \\
Jolene & F & MPU2 & Civil & 6.55 \\
Julie & F & PrU & Mechanical & 5.88 \\
Katherine & F & MPU & Civil & 6.28 \\
Kim & F & LPU & Civil & 5.54 \\
Madison & F & TU & Mechanical & 4.86 \\
Nathan & M & TU & Civil & 6.12 \\
Quinn & M & LPU & Electrical and & 5.33 \\
Rachael & computer & \\
Shawn & F & PrU & Software & 6.10 \\
Tanya & M & LPU & Chemical & 6.46 \\
Todd & F & TU & Environmental & 6.10 \\
Trevor & M & TU & Mechanical & 5.12 \\
Tucker & M & MPU & Civil & 5.52 \\
Wynne & M & LPU & Civil & 5.48 \\
& & LPU & Architectural & 5.88 \\
\hline
\end{tabular}

In these semi-structured interview, students were asked questions about their college courses, significant events, thoughts on social responsibility, and how these are related to their views of their future profession as engineers. These questions had the general goal of eliciting the students' reflections on their time in college overall and their intentions for a future in the engineering profession. One question in particular, Question 4, that was located somewhat early in the interview brought on thoughts about how engineering students valued a positive impact on society in their careers: "What is your current vision of an ideal engineering career?" followed by, "what would be rewarding in a job to you?" These questions preceded directly querying students about their thoughts on social responsibility. The complete set of interview questions can be found in Appendix A.

To counter potential bias in listening to the recorded interviews or reading the transcripts, the two authors (one was the interviewer) independently categorized the twenty students into ideas commonly expressed that answered the research questions listed above. Of the twenty interviews, the two researchers originally disagreed on the categorization of two of the students. The researchers presented evidence about each student's categorization, and came to consensus.

All of the research was conducted according to methods and protocols approved by the Large Public University Institutional Review Board for Human Subjects Research, Protocol 11-0414, and included informed consent before each interview and online survey. 


\section{Results and Analysis}

\section{Emergent Ideal Career Types}

Students responded in many ways about their visions for ideal careers in the future. Most $(n=17)$ had internships that shaped what they would and wouldn't like in a job in the future. Of those who were finishing school $(n=15)$, many $(n=6)$ already had a job lined up, and they envisioned themselves moving up the hierarchy. Many were either planning on taking one or two more semesters to finish their undergraduate degree $(n=5)$ or were continuing on to graduate school $(n=4)$; these students often did not have concrete ideas of what an ideal career would be. While there was a significant diversity in responses, the researchers identified trends that fit into four groups that are distinguished by the degree to which the student described helping people or improving society as integral to a careers desirability, and whether they expressed this desire before or after being asked what would make a career rewarding (Table 2). The types of each student and other demographics are shown in Table 3. For students with internships, the interview in which they discussed this experience are noted in the table. The majority of the internships were during the summer, but some were also during the academic year. Some only or also had academic engineering experience such as undergraduate research, and those are noted with an 'A.'

Table 2: Student Types based on 'Ideal Career' Response

\begin{tabular}{|c|l|c|}
\hline Type & \multicolumn{1}{|c|}{ Description } & \# Students \\
\hline A & Student's main goal for their future career is to improve society or help people. & 3 \\
B & $\begin{array}{l}\text { One of the student's goals for their future career is to improve society or help people. } \\
\text { C }\end{array}$ & $\begin{array}{l}\text { When asked what would be rewarding in their future ideal career, student discusses } \\
\text { meaningful work, helping people, or improving society. }\end{array}$ \\
D & $\begin{array}{l}\text { Student did not express helping people or improving society as a component to their } \\
\text { ideal career or making their engineering work rewarding. }\end{array}$ & 8 \\
\hline
\end{tabular}


Table 3: Student Demographics and Ideal Career Types

\begin{tabular}{|cccccc|}
\hline Pseudonym & $\begin{array}{c}\text { Date Earning } \\
\text { B.S. }\end{array}$ & Internships & $\begin{array}{c}\text { Graduate } \\
\text { Program }\end{array}$ & $\begin{array}{c}\text { Known Job } \\
\text { After College }\end{array}$ & $\begin{array}{c}\text { Ideal Career } \\
\text { Type }\end{array}$ \\
\hline Derek & May 2016 & $4 \mathrm{~A}$ & No & Yes & A \\
Katherine & May 2016 & 3,4 & No & No & A \\
Wynne & May 2016 & 2A,3,4 & No & Yes & A \\
\hline Quinn & May 2017 & None & - & - & B \\
Tanya & May 2017 & 2A, 3A, 4 & Plans & - & B \\
\hline Denise & May 2016 & 1A, 2A,3A, 4A & Yes & No & C \\
Jamie & May 2016 & 4 & No & Yes* & C \\
Jason & May 2017 & 3,4 & No & Co-op & C \\
Jolene & May 2016 & $2,3,4$ & No & Yes & C \\
Julie & May 2016 & $4 \mathrm{~A}$ & Yes & No & C \\
Kim & Dec 2016 & 3 & No & - & C \\
Shawn & May 2016 & None & Maybe future & No & C \\
Todd & Aug 2016 & $2,3,4$ & No & No & C \\
\hline Ashley & May 2016 & $3 \mathrm{~A}, 4$ & No & No & D \\
Brandon & Dec 2016 & $2,3,4$ & No & - & D \\
Madison & May 2016 & $2 \mathrm{~A}, 3,4$ & No & Yes & D \\
Nathan & Dec 2015 & 3,4 & Yes & Yes & D \\
Rachael & May 2016 & $3 \mathrm{~A}, 4$ & Yes & No & D \\
Trevor & May 2016 & None & Maybe future & No & D \\
Tucker & May 2016 & 3,4 & Maybe & No & D \\
\hline
\end{tabular}

*Military after college, non-traditional

Three students indicated that improving society or helping people was a crucial career trait they were seeking (Type A), though they described this sentiment in different ways. Wynne, an architectural engineering student attending LPU, stated that an ideal career would be doing "work where everyone cares about being socially responsible." It seemed that she saw herself being most content in a company that had values that aligned with hers in terms of project choice and going beyond minimum environmental and ethical requirements. Derek, a mechanical engineering student attending PrU, commented that "making a difference" was most important to him, but in quite a different way than Wynne described. Derek saw his ideal career being an Imagineer at Disney because he believed children's experience "inspires them and expands their creativity and gives them something to believe...." Interestingly, he contrasted this ideal career with others that may be more traditional in engineering, noting that "it's not saving anybody's life or getting people from here to there...." The third student, Katherine, was a civil engineering student at MPU; her story will be elaborated on later in the manuscript.

Two students eventually mentioned the importance of helping people or improving society in their future career (Type B). After Tanya discussed flexibility and interesting work, she stressed that she would like a company or projects that "incorporate community involvement." She went on to describe that she would like to be involved with outreach programs through her company. Tanya was an environmental engineering student attending TU. Quinn was an international student majoring in electrical and computer engineering at LPU, and had a very different 
description: to "have an impact," but imagined this would be through a video game by which he would make people happier by entertaining them.

Eight students expressed improving society or helping people as an important component when asked what would make a job rewarding (Type $\mathrm{C}$ ). This additional nudge from the interviewer seemed to be an important distinction from those who prioritized helping as part of their ideal career. Shawn, a chemical engineering student at LPU, said it would be rewarding to "have a decent impact on society," but stated he would like a challenge and to not work excessive hours when describing his ideal career. Denise, a mechanical engineering student at PrU, had a similar perspective saying, "I'm not really going to do work that is purely for making money or purely for, I don't know, war or something...." The type of work she planned on doing needed to align with her morals to a certain extent. This quote also illustrates the common response from many students of describing what they do not want to have in their careers, and that they would avoid certain industries due to their perceived negative impact on society or the environment. Type $\mathrm{C}$ included students in three different majors attending four different institutions.

Seven students fell into the final category (Type D), and never mentioned that improving society or helping people was an aspect taken into consideration when creating an image of an ideal career. Type D included students from 4 different majors attending 4 different institutions. Brandon, a mechanical engineering student attending TU, acknowledged late in the interview after questions about social responsibility that engineers do help society, but he didn't feel it was a priority in directing his career choices right now. He first listed that a job would be rewarding by "a combination of staying busy and always having stuff to do [that is] exciting and challenging enough." Rachael, a software engineering student attending PrU, mainly seemed concerned with her professional colleagues and the interesting technical engineering components in the career pathway she had planned for herself (exploring space with robotics and computer programming). She described her rewarding components as, "the people I'm working with because the teams that I' $m$ on really make progress...towards a larger goal," and "seeing that progress and knowing that I worked on that." She did, however, make vague references to the potential development of other planets and the macro scale improvements that could have.

\section{Detailed Accounts from Four Students}

With a better understanding of the different types into which the students were categorized, the following section will provide a deeper understanding of one student of each career type, providing a richer excerpt from their interview. This will frequently include the Interviewer question (I) that led to the student response. The influences that appeared to contribute to these beliefs will also be discussed to lead into some recommendations for engineering programs and faculty who want to improve the pro-social goals of their graduating engineering students.

\section{Type A: Katherine}

Katherine was a graduating civil engineering major attending a medium-sized public university. She was categorized as a Type A due to the strong social motivation present in her response to the question about her ideal career, and that it was the first component she mentioned:

I would really like to be in a position where I feel like that I am making a difference, but it would be a difference that helps the larger population so whether it's something like a 
public works engineer if you're working for a town or city, you know you have one client all of the time and you are just working to improve their condition. I just really like that idea. I think that's a really valuable mission.

Katherine had an internship with a city public works department and she was able to see the impact that their works had on the city in which she lived. From her quote, it seems that this was a powerful experience that connected her civil engineering major with practical improvements in the community. She further demonstrated how she valued having a positive impact on society when she was asked about what would be rewarding in a future career:

I: What would make the job rewarding for you?

$\mathrm{K}$ : I think it would just be having a positive impact, so whether that be making a system more efficient so it leaks less water and is better for the environment or whether it makes people's daily lives a little bit easier, I think just sort of having a positive impact on the society or generally is really a position I want to be in.

I: Why do you want that?

$\mathrm{K}$ : I think because it's kind of why else do it? Why else spend the money to do something if it's not going to be improved in a positive way? In general, engineering designs are very expensive, and I think it's one of those things that if you're going into design then you should aim to have a really good design. So yeah, I think it's just logical to make something better and have a positive outcome from that.

Katherine seemed to clearly understand her job as an engineer as much more than a paycheck, and that the work she will be performing will be rewarding as it inherently is valuable to society. While she does not yet have a job, it is reasonable to assume that she will find her civil engineering work satisfying.

\section{Type B: Tanya}

Tanya was an environmental engineering student at a technical university (TU) who, at the time of the interview, still had two more semesters until graduation. Throughout her time in college she had many experiences that seemed to contribute directly to what she identified as important in a future career. She worked two summers as a research assistant and then had an internship with an environmental consulting company. She also was heavily involved with the National Society of Black Engineers (NSBE), particularly the outreach programs, and was the president during her fourth year. Her plans after she graduated were to attend graduate school and "complete my Master's at least". In the interview, she first described the technical components of her ideal career, to do research that would include field work and laboratory analysis.

I: how about an ideal engineering career, what does that look like for you?

T: Right now, it would be more like research and development. So it would be basically in a lab and doing research in going on to the field and collecting samples and getting data.... 
Then, the interviewer phrased the question a little differently, which seemed to access another important component:

I: What else about that an ideal job, what else is there from the day to day or more broad understanding of the values of the job?

T: I would like a job that is flexible. Not like just do whatever, but I would like a job that is a lot to do with the community and incorporates community involvement. They should have good benefits for their workers.

I: Can you tell me more about the community involvement that you are thinking of?

T: So it could be anywhere from working with schools like high schools or middle schools or it could be making opportunities for the community that, for example if I had to pick something, I would say like working with an after-school program or authoring a high school unit or college unit or something like that.

I: So these would be outside of your actual technical engineering work?

T: Yeah, but some companies set it up so that you get paid to work with the community also. That would be a pretty good idea, too.

Tanya learned about ways that she could engage through her future job with the communities that were important to her from her upbringing and outreach efforts in NSBE. She described in other interviews that she believed one of the best ways she could use her career as an engineer would be to expose students in underprivileged communities to engineering as a potential career path. While different from Katherine's statements above about the work itself contributing to improving society, Tanya's ideas for community engagement are also very valuable to the engineering profession in the context of the NAE's Changing the Conversation ${ }^{10}$.

\section{Type C: Jason}

Jason was a civil engineering student focusing on water resources at TU. He still needed one more semester to finish his degree and was planning on doing a co-op through the summer and following Fall. His understanding of the impact of his potential engineering career in the future seemed to be shaped largely by his classes since his summer jobs and internships did not quite align with what he was learning about water resources in his classes. He learned about what he did and did not want in the practicalities of the job, but less about the impact. The following excerpt gives a deeper glimpse into Jason's thoughts and values about work in the future:

I: What do you see right now as an ideal engineering career for yourself? What would be the factors and components of that job?

$\mathrm{J}$ : Actually, the civil engineers and to better the deal, they don't make all kinds of money, but it is stable and it's there all the time and so it's a constant I guess. Yeah, some of it is that you can count on it being flexible and it's nice....

I: What are the things that you are looking for besides it being stable and flexible? 
J: Well I think it's just that I'd like to be doing what I'm setting myself up for, or not too far off. I'd like to do water resources; that would be nice to do something like that. The degree doesn't mean that I have to do that exactly, but it is what I would like to do. It's the most interesting to me. And I think the work environment, like where, what the people there are like and stuff.

I: Yeah, it's important. What would make a job rewarding to you?

$\mathrm{J}$ : I guess one of the things that I like about the construction aspect is that all the stuff is actually happening. Actually seeing the stuff built would be really cool. Another job would be really neat and I think I would like that, but I like to be in the field and see stuff happening and see it through to completion, I guess, rather than handing it off to someone else or whatever.

I: Anything else that would make it rewarding do you think?

$\mathrm{J}$ : I mean, I guess what I'd like to do is try to help people, which is important to me, but that's what goes with the territory and I think that's what I'm getting into. The kind of work that I'm looking at, it's a given that it's going to be beneficial to the community or to society or the environment as a whole. That's the whole point of the water resources that I'm going for.

What seemed rather important in Jason's responses was the succession of components he mentioned in his ideal career: Then when asked what would be rewarding the second time, he talked about benefit to the community and society. If not read with the rest of that portion of the interview, his response actually seems quite similar to Katherine's. It is unclear exactly how he would prioritize these when actually choosing between jobs, but perhaps he believes that the job will inherently be positive for society, so he should be more concerned with other matters such as stability and flexibility.

Type D: Ashley

Ashley was a graduating chemical engineering student at a private university and she did not have a job lined up following graduation. In the previous summer she was an intern at a brewery getting a practical education, but with less technical engineering work that related to her courses in college. She reported that the job was "maybe 30\% [engineering] when I had to figure out how to do things and be a problem solver." Of her previous undergraduate research during her junior year she commented, "I learned that I don't like academic research or being in a lab. It's not for me ...." Otherwise, she had not experienced the engineering profession beyond her curriculum. In the interview, she was asked in multiple ways what would make an ideal career and what would be rewarding, and having an impact on society or helping people was not mentioned. As for Jason above, a longer portion of the transcript is presented below to demonstrate how she valued different elements of her envisioned future career:

I: So I guess, how are you prioritizing the jobs like if you had multiple offers, how would you prioritize in making that decision?

A: I guess the main thing would be, 'do I see myself at the company and do I see myself enjoying going work every day?' That would be number one, but number two would be 
the location. Like, am I in the middle of nowhere or am I enjoying myself and enjoying where I'm living? I definitely prefer more of the city living, and I have been over a lot of my life not really in a city. I think the third would be I guess, like money. If it does come down to money, that would be something, but first the culture and do I see myself there and is it something I would enjoy and then the location and then the money.

I: ...what is your current vision for an ideal engineering career?

A: Um, I'm not exactly sure. I really wanted to do something and I think right now it's just like I need to get a job, and if it's the job in a bad location then I feel like just in the next four years I will have enough experience built up, and I could choose a location I would like to work in and I could choose a company that I feel is really good and has a really good culture surrounding it. I guess just enjoying going to work each day would be ideal.

I: ...what are some of those factors that would make a job particularly rewarding?

A: I guess part of it is seeing a product and saying that I have done something or that I've created a change or that I have created something and what I did was acceptable and I worked on a product and helped it come to fruition. I think that those are things that look for in a job.

Ashley discussed multiple specifics of her ideal job, and expressed that completing a project would be rewarding, doing "acceptable" work. Her vague language about doing "something" and creating "a change" are potentially areas that she recognizes would be rewarding and important to her, but she may not have the specifics upon which to draw due to her minimal professional experience. Also, her chemical engineering courses may not have demonstrated the impact her work could have as it did for Jason and other students.

\section{Discussion}

The above data confirm what others have found in studies cited in the introduction. Many engineering students may inherently see that their profession is beneficial to society, and they will not need to consider explicitly the impacts that their work could have. As they are not typically encouraged to consider this in their classes, it is perfectly reasonable for them to not make the connections or to value other factors that seem more immediate in their own quality of life such as coworkers, interesting work, and location.

Professional experiences and the proximity of job-seeking after graduation also may have an effect. The two Type B students, Quinn and Tanya, were not graduating for another year, so perhaps they were not looking at the jobs available at the time of the interview and trying to make decisions about what day-to-day components they would need to be happy in their jobs. Internships experiences seem to be dependent on the particular job and work environment that may or may not align with the students' interests and values.

The extent to which the students' perceived satisfaction with their future careers contributed to their retention in their engineering programs is unclear as the authors chose not to ask this directly in the interviews. Following from the other literature cited previously, though, there is 
reason to believe this was a factor for some students. Katherine wanted to improve society through her future career, and found she was able to do that through engineering.

Somewhat different pictures of students' priorities emerged from the interviews as compared to the online survey. For example, in the online survey taken by 19 of the 20 interviewees near the time of the interviews, individuals were asked "To what extent will your ability to help people or society though your work motivate you to select a particular job? Select the answer that is most representative of your views." Responses are shown in Table 4.

Table 4: Survey Responses Regarding Ability to Help People or Society as a Motivation to Select a Particular Job

\begin{tabular}{|ll|}
\hline Response Option & Respondents Selected \\
\hline Not a factor in the decision & Madison \\
$\begin{array}{l}\text { If I feel I can do this, it would be a somewhat positive } \\
\text { factor in my decision }\end{array}$ & $\begin{array}{l}\text { Brandon, Derek, Jamie, Jason, Julie, } \\
\text { Katherine, Kim, Nathan, Rachel, } \\
\text { Shawn, Todd, Tucker, Wynne }\end{array}$ \\
$\begin{array}{l}\text { If I don't feel that I can do this, I may not take the job } \\
\begin{array}{l}\text { This is the primary factor that I will use to select a } \\
\text { job }\end{array}\end{array}$ & \begin{tabular}{l} 
None \\
\hline
\end{tabular} \\
\hline
\end{tabular}

None of the 20 interviewees selected the "primary factor" option; among 83 responses to this question among a larger survey pool, only a single student selected this choice (a female chemical engineering student from PrU who was uncertain whether she would work as an engineer or in a related field after college). We might have expected the Type 1 individuals to have selected the "primary factor" category based on their interview responses. Another survey item asked students "When considering a full-time job, select the top five criteria that are most important to you"; among the 10 choices, "impact of work on the world" was selected by 9 of the 19 interviewees (bold in Table 4). The results seem to show a contrast between Ashley's interview responses (categorized as group D) and her survey responses. This seems important as more depth beyond surveys may be needed to accurately capture students' attitudes, or perhaps it shows the impact of directly asking questions that may bias responses.

For engineering educators and programs, it seems some practical steps could be made to increase the extent to which students have career goals more directly tied to improving society and helping people. As mentioned, many students had professional experiences outside of their university that were impactful on their perception of a future career, and fewer discussed courses or faculty that gave them an idea of the impact of engineering work. Faculty have a wealth of knowledge and experiences that could be shared with students in order to make these connections. Discussions within engineering classes about the social and human relevance of particular topics and case studies would help not only to improve the perception of engineering's value to society, but will also make the content come alive.

Further, career centers and advisors could work with companies such that more of an emphasis is placed on the social impact of the job than the salary or advanced technology. One other suggestion is to continue encouraging student involvement with co-curricular activities. Many of 
these complement and connect classroom learning with the real world and allow students to experience the impacts of engineering works in a more real way before entering the profession. Tanya was heavily involved with NSBE, Quinn worked with his peers on a better respirator, Wynne was active in the Society of Women Engineers, and Derek was a student-athlete involved through which he engaged with the local community.

Finally, an outcome of engineering education should be that all students think more clearly about how 'good engineering' includes working in an ethical manner which means attention to genuine engagement of all stakeholders and macroethical issues. All students should be able to see their potential in any engineering job to help people and society versus the notion that only a limited range of job types accomplish these goals. Anyone involved with engineering students' education has a role to play in making this reality clear.

\section{Limitations and Future Work}

Limitations in time or the students' tangents that took the interview in a different direction are some of the hazards of semi-structured interviews with students of varying personalities. It is entirely possible that the students held beliefs that they did not share or the interviewer did not ask the right questions to elicit a response about impacting society and helping people.

As four years of interviews have vast amounts of content, the research team will continue to analyze longitudinal trends related to social responsibility using both the qualitative and quantitative data. From this study, one journal paper is under review regarding SR attitudes and ideas of students who left their engineering major. Two more are forthcoming regarding engineering students' changing ideas about socially responsible engineering and engineers. Additionally, a large quantitative study has been ongoing to get a broader understanding of the impacts on SR attitudes of engineering students and to see if there are any demographic-related reasons for differences in SR beliefs. Following a further understanding of engineering students' SR attitudes and desires for social impact, comparisons can be made between areas of study and practice such as law, health, education, and others. Connections may be made between the reasons for students' enrollment in the field of practice, their perception of the different professions, and emphases within the curricula.

In applying these study results within the classroom, students could engage in an advanced stakeholder network activity that would show them practically how their projects within the course or in their predicted future careers would impact society more broadly. These indirect and often hidden effects of engineering projects, historically and in the future, are highly interesting to students and will make engineering works in the classroom become relevant to social issues to which students are exposed through mass media. A new course at the Colorado School of Mines entitled 'Engineering for Social and Environmental Responsibility' will attempt to do just that in the Fall of 2017.

\section{Conclusions}

The broad range of students in this study evidenced significant variations in the extent to which helping others was a priority in their ideal career and/or a factor that would contribute to making 
their job rewarding. Type clustering did not align with any particular institutions or disciplines. A few seemed to place very high value on improving society through their job, and a couple more believed it was necessary to their ideal career. The majority of students, however, when given a chance to explain their ideal career at length, did not include the macro-level impacts that their career could have on people and society. While it is encouraging that students find the positive impact of their work rewarding, the evidence suggests that this component would not be necessary to raise concerns. To make the most positive effects on the world, it seems that individual engineers would need to strive to make their careers improve society. This could then translate to an engineering profession that places overall societal benefits above the needs of individual clients and corporations.

\section{Acknowledgments}

Some of this material is based on work supported by the National Science Foundation under Grant \#1158863. Any opinions, findings, and conclusions or recommendations expressed in this material are those of the author(s) and do not necessarily reflect the views of the National Science Foundation.

\section{Works Cited}

1. Layton Jr, E. T. The Revolt of the Engineers. Social Responsibility and the American Engineering Profession. (ERIC, 1986).

2. Wisnioski, M. Engineers for change: Competing visions of technology in 1960s America. (MIT Press, 2012).

3. Vesilind, P. A. Evolution of the American Society of Civil Engineers code of ethics. Journal of professional issues in engineering education and practice 121, 4-10 (1995).

4. Luegenbiehl, H. C. \& Davis, M. Engineering Codes of Ethics: Analysis and Applications. (1992).

5. Lucena, J. C. Defending the Nation: U.S. Policymaking to Create Scientists and Engineers from Sputnik to the 'War Against Terrorism'. (University Press of America, 2005).

6. Litchfield, K., Javernick-Will, A. \& Paterson, K. Exploring EWB-USA Members' Descriptions of Self, Engineers, and their Fellow Members. International Journal for Service Learning in Engineering 9, 24-39 (2014).

7. Herkert, J. R. Ways of thinking about and teaching ethical problem solving: Microethics and macroethics in engineering. Science and Engineering Ethics 11, 373-385 (2005).

8. Douglas, D., Papadopoulos, G. \& Boutelle, J. Citizen Engineer: A Handbook for Socially Responsible Engineering. (Prentice Hall, 2009). 
9. National Academy of Engineering. The Engineer of 2020: Visions of Engineering in the New Century. (National Academies Press, 2004).

10. National Academy of Engineering. Changing the Conversation: Messages for Improving Public Understanding of Engineering. (National Academies Press, 2008).

11. Grant, A. M. \& Berg, J. M. Prosocial motivation at work: When, why, and how making a difference makes a difference. Oxford handbook of positive organizational scholarship. Oxford University Press, New York 28-44 (2011).

12. Schreuders, P. D., Mannon, S. E. \& Rutherford, B. Pipeline or personal preference: women in engineering. European Journal of Engineering Education 34, 97-112 (2009).

13. Eccles, J. in Why Aren't More Women in Science? 199-210 (American Psychological Association, 2007).

14. Tsui, L. Overcoming barriers: Engineering program environments that support women. Journal of Women and Minorities in Science and Engineering 16, (2010).

15. Bielefeldt, A., Paterson, K. \& Swan, C. Measuring the Impacts of Project-Based Service Learning. in American Society of Engineering Education (2009).

16. Cech, E. A. Culture of Disengagement in Engineering Education? Science, Technology \& Human Values 39, 42-72 (2014).

17. Baillie, C. \& Levine, M. Engineering Ethics from a Justice Perspective: A Critical Repositioning of What It Means To Be an Engineer. IJESJP 2, 10-20 (2013).

18. Roeser, S. Emotional engineers: Toward morally responsible design. Science and engineering ethics 18, 103-115 (2012).

19. Bielefeldt, A. R. \& Canney, N. E. Changes in the Social Responsibility Attitudes of Engineering Students Over Time. Science and Engineering Ethics 1-17 (2015).

20. Rulifson, G. A., Bielefeldt, A. \& Thomas, W. Understanding of Social Responsibility by First Year Engineering Students: Ethical Foundations and Courses. in American Society for Engineering Education Conference and Exposition Proceedings (2014).

21. Rulifson, G. \& Bielefeldt, A. Engineering Students' Varied and Changing Views of Social Responsibility. in (2015).

22. Rulifson, G. A. Evolving social responsibility understandings, motivations, and career goals of undergraduate students initially pursuing engineering degrees. (2015).

23. Canney, N. \& Bielefeldt, A. A Framework for the Development of Social Responsibility in Engineers. International Journal of Engineering Education (2014). 
24. Miles, M. B., Huberman, A. M. \& Saldaña, J. Qualitative Data Analysis: A Methods Sourcebook. (SAGE, 2013).

25. Ogden, R. Pseudonym. The SAGE encyclopedia of qualitative research methods 693-694 (2008). 
Appendix A: Fourth Year Interview Questions

1. Will you tell me your major and your year in school?

2. Tell me about the last year: some highlights and events or activities that were especially important to you.

3. What are your plans for the coming year following graduation?

4. What is your current vision for an ideal engineering career? a. What factors would make a job personally rewarding to you?

5. What will be your responsibilities as an engineer? Think narrowly and broadly about the term 'responsibilities.'

a. Who will you be responsible for as an engineer?

6. What are some ways that you think about social responsibility?

a. Has your understanding changed much in the last year? Why do you think that is?

b. How have your ideas about social responsibility generally changed during college?

Why do you think that is?

7. How do you think your ideas around personal social responsibility influence your ideas about professional responsibility and vice versa?

a. If different from responsibilities of an engineer, ask how they deal with the difference.

8. In what ways do you believe that you might be serving or helping people and/or society in some way during your career?

a. To what extent is this helping aspect of the job important to you?

b. How does the importance of helping compare with other factors such as salary, location, who you work with, etc.?

9. In what ways do you believe that your vision of how you might help society and/or people through your career as an engineer has changed since you began college? What experiences have contributed to these changes?

10. After you graduate, in what ways might you like to help people and/or society outside your work?

11. Is there anything else you would like to share, or do you have any questions?

12. Did these interviews affect the ways you think about social responsibility? 